$<0.05)$. The groups did not differ in terms of activity indicators and the presence of extra-axial manifestations.

Table 1. Characteristics of patients with axSpA at the time of inclusion in the study who had PRC after 24 months of observation.

\begin{tabular}{llll}
\hline Parametrs & $\begin{array}{l}\Delta \text { BASRI hip=0 } \\
\mathrm{n}=33\end{array}$ & $\begin{array}{l}\Delta \text { BASRI hip }>0 \\
\mathrm{n}=44\end{array}$ & $\mathrm{p}$ \\
\hline Sex (m/w), $\mathrm{n}$ & $22 / 11$ & $32 / 12$ & $>0,05$ \\
The duration of the disease, m., Me [25;75\%] & $36[19 ; 132]$ & $48[24 ; 84]$ & $>0,05$ \\
Age, years, Me [25;75\%] & $30[26 ; 34]$ & $28[24 ; 34]$ & $>0,05$ \\
BASDAI, Me [25;75\%] & $4,3[3,1 ; 5,8]$ & $4,7[3,8 ; 6,3]$ & $>0,05$ \\
BASFI, Me [25;75\%] & $3,4[0,6 ; 5,6]$ & $2,1[1,1 ; 4,2]$ & $>0,05$ \\
ASDAS (SRP), Me [25;75\%] & $2,6[1,6 ; 3,9]$ & $3,2[2,3 ; 4,2]$ & $>0,05$ \\
ESR, mm/h, Me [25;75\%] & $15[7 ; 30]$ & $23,0[12 ; 35]$ & $>0,05$ \\
SRP, mg/l, Me [25;75\%] & $12,8[1,8 ; 31,0]$ & $17,8[5,6 ; 50,3]$ & $>0,05$ \\
Peripheral arthritis, n \% & $26(79 \%)$ & $32(73 \%)$ & $>0,05$ \\
US synovitis n\% & $19(58 \%)$ & $44(100 \%)$ & $<0,05 *$ \\
Pain in HJ n\% & $28(85 \%)$ & $38(86 \%)$ & $>0,05$ \\
\hline
\end{tabular}

Conclusion: X-ray progression of coxitis is associated with ultrasound synovitis and does not depend on the activity of the disease.

Disclosure of Interests: None declared.

DOI: 10.1136/annrheumdis-2021-eular.2002

\begin{tabular}{|l|l}
\hline AB0499 & PHYSICAL ACTIVITY ASSESSMENT IN TUNISIAN \\
PATIENTS WITH SPONDYLOARTHRITIS: THE IPAQ \\
EVALUATION
\end{tabular}

F. Majdoub ${ }^{1}$, M. Sellami ${ }^{1}$, S. Miladi ${ }^{1}$, A. Fazaa ${ }^{1}$, L. Souabni ${ }^{1}$, K. Ouenniche ${ }^{1}$, S. Kassab ${ }^{1}$, S. Chekili ${ }^{1}$, K. Ben Abdelghani ${ }^{1}$, A. Laatar ${ }^{1} .{ }^{1}$ Mongi Slim Hospital, Rheumatology, La Marsa, Tunis, Tunisia

Background: The occurrence of Spondyloarthritis (SpA) often conditions patients' quality of life and hinders their well-being. Physical activity (PA) is associated with various health-related benefits among adults with chronic inflammatory rheumatism but may be insufficiently performed.

Objectives: This study aimed to assess PA in patients with $\mathrm{SpA}$ and explore its associated factors.

Methods: This is a single-center cross-sectional study, involving patients with $\mathrm{SpA}$, visiting our outpatient hospital over eight weeks. Patients responded to the International Physical Activity Questionnaire-Short form (IPAQ-S).

Results: Sixty patients were included $(39 \mathrm{M} / 21 \mathrm{~F})$ with an average age of 45.8 years [25-78]. The mean duration of SpA was 13.2 years [1-25]. About $80 \%$ of patients were from an urban setting. Sixty-three percent of patients had a professional activity, while $13.3 \%$ were retired. Twenty-nine patients $(48.3 \%)$ had axial and peripheral form, 18 patients $(30 \%)$ had SpA with enteropathic arthritis, 8 $(13.3 \%)$ with psoriatic arthritis, 3 patients $(5 \%)$ had axial spondyloarthritis, and only 2 patients $(3.3 \%)$ with SAPHO-Syndrom. About $23 \%$ of patients had hip arthritis and only $5 \%$ had uveitis. Fifty-eight patients were on TNF-inhibitor (21/58 Adalimumab, 15/58 Infliximab, 14/58 Etanercept, 8/58 Golimumab). The average BASDAI was 2.7/10. The average ASDAS $_{\text {CRP }}$ was 2.1/10. The average BASFI was 3.3/10. IPAQ results were distributed as follows: $78.3 \%$ of patients were in the «low physical activity » category, $21.7 \%$ were in the « moderate physical activity » while none of the patients were in the « high physical activity ». Patients without employment had lower levels of physical activity $(29.7 \%)$ but no association was observed between those two items $(p=0.082)$. Disease activity objectified with BASDAI was related to low physical activity $(p=0.045)$ whereas no association was observed with ASDAS $_{\text {CRP }}(p=0.870)$ or BASFI $(p=0.056)$. Otherwise, TNF-inhibitor treatment was not related to different levels of PA $(p=0.09)$. Conclusion: Tunisian patients with SpA don't perform enough physical activity. Except for high disease activity, the different levels of PA did not appear to be explained by other disease-related variables. Thereby, physical activity should be encouraged in SpA.

REFERENCES:

[1] Fabre, S., Molto, A., Dadoun, S. et al. Physical activity in patients with axial spondyloarthritis: a cross-sectional study of 203 patients. Rheumatol Int 36 , 1711-1718 (2016).

Disclosure of Interests: None declared.

DOI: 10.1136/annrheumdis-2021-eular.2053

\section{AB0500 IMPACT OF COVID-19 PANDEMIC IN OVERALL HEALTH AND FUNCTIONING IN PATIENTS WITH AXIAL SPONDYLOARTHRITIS: RESULTS FROM THE REUMAVID STUDY (PHASE 1)}

D. Benavent ${ }^{1}$, M. Garrido-Cumbrera ${ }^{2,3}$, C. Plasencia ${ }^{1}$, L. Christen ${ }^{4}$, H. Marzo$\mathrm{Ortega}^{5}$, J. Correa-Fernández ${ }^{2}$, P. Plazuelo-Ramos ${ }^{3}$, D. Webb ${ }^{6}$, V. NavarroCompán ${ }^{1}{ }^{1}$ Hospital La Paz, IdiPAZ, Rheumatology Department, Madrid, Spain;
${ }^{2}$ Universidad de Sevilla, Health \& Territory Research, Sevilla, Spain $;{ }^{3}$ Axial Spondyloarthritis International Federation (ASIF), London, United Kingdom; ${ }^{4}$ Novartis Pharma, AG, Basel, Switzerland; ${ }^{5}$ University of Leeds, NIHR Leeds Biomedical Research Centre, LTHT and LIRMM, Leeds, United Kingdom; ${ }^{6}$ NASS, London, United Kingdom

Background: Evidence on the impact of the COVID-19 pandemic on the overall health and functioning in patients with axial spondyloarthritis (axSpA) is scarce. Objectives: To analyse the impact of the COVID-19 pandemic on the overall health and functioning in patients with axSpA.

Methods: Data from axSpA patients participating in the first phase of the REUMAVID study were analysed. REUMAVID is a cross-sectional, observational study collecting data through an online questionnaire of unselected patients with rheumatic and musculoskeletal diseases (RMDs), recruited by patient organizations. The survey was disseminated during the beginning of the COVID-19 pandemic (April-July 2020) in seven European countries (Cyprus, France, Greece, Italy, Portugal, Spain, and the United Kingdom). Patients with axSpA who completed the ASAS health index (ASAS-HI) questionnaire were included in this analysis. Descriptive analyses were used to present socio-demographic and clinical characteristics, as well as daily habits. Overall health and functioning were defined according to the ASAS-HI (0-17), as follows: good health (ASAS-HI $\leq 5$ ), acceptable health (ASAS-HI $6-11$ ), and poor health (ASAS-HI $\geq 12$ ). As secondary outcomes, well-being (WHO-5), self-perceived health status, and HADS for anxiety and depression were assessed.

Results: Out of 670 axSpA patients, 587 (87.6\%) completed ASAS-HI. Of these $70.4 \%$ were female, $72.6 \%$ were married or in a relationship, $46.7 \%$ had university studies and $37.6 \%$ were currently employed. Mean age was $49.9 \pm 12.8$ years and mean BMI was $26.7 \pm 5.5$. Regarding extraarticular manifestations, $13.6 \%$ had psoriasis, $12.1 \%$ inflammatory bowel disease and $18.7 \%$ uveitis. Before the COVID-19 pandemic, $50.9 \%$ were receiving biological drugs, $46.3 \%$ NSAIDs, $26.4 \%$ painkillers, $24.7 \%$ conventional DMARDs, and $11.9 \%$ oral corticosteroids. According to the ASAS-HI, $19.6 \%$ of patients were classified as having poor health, with the most affected aspects being pain $(92.0 \%)$, movement $(86.5 \%)$, maintenance of body position $(80.6 \%)$, energy $(79.0 \%)$ and sleep $(75.3 \%)$. Regarding self-perceived health status, $14 \%$ reported their health status as "bad" or "very bad", and $46.8 \%$ reported worsening health during the pandemic (Table 1). A distribution of the results of the total ASAS-HI scores can be seen in Figure 1.

Table 1. Overall health and well-being, disease activity, and mental health.

\begin{tabular}{|c|c|}
\hline Primary Outcome (ASAS-HI) & $\begin{array}{l}\text { Mean } \pm \text { SD or } \\
n(\%)\end{array}$ \\
\hline ASAS-HI (0-17), $n=587$ & $8.0( \pm 3.9)$ \\
\hline \multicolumn{2}{|l|}{ ASAS-HI } \\
\hline$<5$ (good health) & $159(27.1)$ \\
\hline 5-12 (acceptable health) & $313(53.3)$ \\
\hline$\geq 12$ (poor health) & $115(19.6)$ \\
\hline \multicolumn{2}{|l|}{ Secondary Outcomes } \\
\hline \multicolumn{2}{|l|}{ WHO-5 } \\
\hline WHO-5, (0-100), n=584 & $46.3( \pm 23.1)$ \\
\hline WHO- 5 Poor wellbeing WHO- $\leq 50$ & $330(56.5)$ \\
\hline \multicolumn{2}{|l|}{ Self-perceived health status, $n=585$} \\
\hline Very good & $33(5.6)$ \\
\hline Good & $214(36.6)$ \\
\hline Fair & $256(43.8)$ \\
\hline $\mathrm{Bad}$ & 69 (11.8) \\
\hline Very bad & $13(2.2)$ \\
\hline \multicolumn{2}{|c|}{ Change in health status during lockdown, $n=587$} \\
\hline Much worse than before & $54(9.2)$ \\
\hline Moderately worse & $220(37.6)$ \\
\hline Same as before & $270(46.0)$ \\
\hline Moderately better & $35(6.0)$ \\
\hline Much better than before & $6(1.0)$ \\
\hline \multicolumn{2}{|l|}{ HADS } \\
\hline HADS Anxiety $(0-21), n=587$ & $8.4( \pm 4.1)$ \\
\hline \multicolumn{2}{|l|}{ HADS Anxiety } \\
\hline No case $(0-7)$ & $248(42.7)$ \\
\hline Borderline case (8-10) & $151(26.0)$ \\
\hline Case (11-21) & $182(31.3)$ \\
\hline HADS Depression (0-21), $n=587$ & $7.0( \pm 4.3)$ \\
\hline \multicolumn{2}{|l|}{ HADS Depression } \\
\hline No case $(0-7)$ & $329(56.6)$ \\
\hline Borderline case $(8-10)$ & $134(23.1)$ \\
\hline Case (11-21) & $118(20.3)$ \\
\hline
\end{tabular}

